\section{NOVA TELLVS}

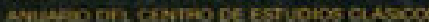

Nova Tellus

ISSN: 0185-3058

novatelu@servidor.unam.mx

Centro de Estudios Clásicos

México

García Pérez, David

La angustia del ser y del deber en la tragedia griega

Nova Tellus, vol. 26, núm. 2, 2008, pp. 103-120

Centro de Estudios Clásicos

Distrito Federal, México

Disponible en: http://www.redalyc.org/articulo.oa?id=59115497004

- Cómo citar el artículo

- Número completo

- Más información del artículo

- Página de la revista en redalyc.org

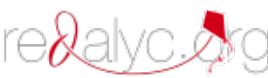

Sistema de Información Científica

Red de Revistas Científicas de América Latina, el Caribe, España y Portugal

Proyecto académico sin fines de lucro, desarrollado bajo la iniciativa de acceso abierto 


\title{
La angustia del ser y del deber en la tragedia griega
}

\author{
David GARCÍA PÉREZ \\ Universidad Nacional Autónoma de México \\ prometeo9@att.net.mx
}

RESUMEN: En este trabajo se explora la definición de lo trágico partiendo de la comprensión de la angustia en algunas tragedias griegas. El sentimiento de la angustia nace cuando el sujeto se ve obligado a definir su ser, hecho que se opone la mayoría de las veces a su deber; en la confrontación de ser y de deber, nace la tensión trágica que se revela, entre otros procesos, con la máscara y la metamorfosis.

ABSTRACT: In this article the definition of tragic is explored starting from an understanding of anguish in some Greek tragedies. The feeling of anguish arises when the character is forced to define his/her own being, which is mostly opposed to his/her duty. It is from the clash between actual being and "should-be" that tragic tension arises, as this is revealed, among other means, through the mask and the metamorphosis.

PALABRAS CLAVE: angustia, deber, máscara, metamorfosis, ser, tragedia griega. RECEPCIÓN: 5 de septiembre de 2008.

ACEPTACIÓN: 29 de octubre de 2008. 


\title{
La angustia del ser y del deber en la tragedia griega*
}

\author{
David GARCÍA PÉREZ
}

La dimensión de la tragedia humana fue el objeto de reflexión del teatro griego clásico, pero, quizá, los mismos griegos no alcanzaron a comprender el ahondamiento del pensar trágico que perfilaron en sus piezas dramáticas, y a nosotros nos está vedado también ese espacio abisal. Lesky ha hecho notar que si bien es cierto que los griegos fueron los creadores de la tragedia como género literario, también lo es que "no desarrollaron ninguna teoría de lo trágico", y más aún la "concepción del trágico acontecer [...] se perdió en gran parte en el helenismo posterior". ${ }^{1}$ En efecto, cuando Aristóteles emprende la tarea de su Poética, pasa por alto qué es el personaje trágico en el sentido indicado por Lesky, esto es, la razón y la trascendencia de la tensión trágica. Una razón de ello es que las fibras de lo trágico refieren pensamientos y pasiones en constante dialéctica, no sólo por la naturaleza propia del teatro, sino porque los poetas trágicos griegos colocaron al sujeto, desde diferentes ángulos de la existencia, en la irrecusable necesidad

\footnotetext{
${ }^{*}$ Este trabajo fue presentado originalmente como conferencia en el marco del II Coloquio Internacional Noua tellus, y se consigna como parte del proyecto "Teatro clásico grecolatino y su tradición en Occidente" (PAPIIT IN-403308), UNAM.

${ }^{1}$ Albin Lesky, La tragedia griega, Barcelona, El acantilado, 2001, p. 37. Cf. Jean-Pierre Vernant, "Tensiones y ambigüedades en la tragedia griega", en J.-P. Vernant y Pierre Vidal Naquet, Mito y tragedia en la Grecia antigua, vol. I, Barcelona, Paidós, 2002 (1972), pp. 23-43.
} 
de ser para sí y para el mundo, y en el motor del deber. Deber que nace de la decisión, acto trágico por naturaleza del individuo pleno de angustia, porque, al decidir, su condición se confronta. Ser y deber se oponen en el sujeto dando origen a una imagen y comprensión de lo trágico.

Las piezas de la tragedia ática que conservamos es el material que permite observar y comprobar que una teoría de lo trágico es poco menos que imposible en la medida en que los sujetos manifiestan la tensión trágica de muy diversos modos. En todo caso se puede decir que en aquéllas se formulaba constantemente la dimensión de la tragedia. Así, el personaje trágico y su conciencia brotaban en el escenario con nuevas aristas, tantas como fuera la magnitud de la oposición del ser y de su deber.

Plutarco reseña que ya en el siglo $\mathrm{V}$ el público asistente a los espectáculos del drama se preguntaba ante el desarrollo temático de las tragedias: “¿En qué atañe esto a Dionisio?”2 Esta pregunta, que se convirtió en un refrán, ha sido entendida y explicada por la mayoría de los exegetas, siguiendo precisamente el comentario de Plutarco, en relación con el origen religioso del teatro, propiamente del ámbito dionisiaco, ${ }^{3}$ lo que, en principio, podría parecer obvio. ${ }^{4}$

Sin embargo, creemos que otro sentido es lícito: el drama dionisiaco presenta en sí los extremos de la pasión humana. Entre el dolor y la risa se manifiesta la psique del sujeto, que

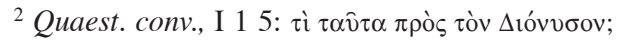

${ }^{3}$ Cf. Jean-Pierre Vernant, "El dios de la ficción trágica", en J.-P. Vernant y Pierre Vidal Naquet, Mito y tragedia en la Grecia antigua, t. II, Barcelona, Paidós, 2002 (1972), pp. 21 y ss.

${ }^{4}$ Sorprende leer a Karl Kerenyi, Dionisios. Raíz de la vida indestructible, Barcelona, Herder, 1998 (1994), pp. 227-228, al señalar que el refrán consignado por Plutarco obedecía a razones del gusto de los atenienses ante lo que presenciaban en el teatro: "Si la frase se hubiera referido exclusivamente al tema de una obra, sólo un mínimo número de tragedias habría tenido algo que ver con Dionisios. No era un rechazo material, sino un juicio relativo a la superficialidad de una pieza, a su nula relación con el dios en cuyo recinto sagrado se representaba".
} 
cobra presencia en la catarsis. Ésta se muestra como una esperanza, pero que, al ser siempre en potencia, ahonda acremente el sentimiento trágico. Puesto que la catarsis del personaje central queda en suspenso, entonces, como parte de la trama narrativa, la angustia se abisma. De un ritual catártico, el ritual dionisiaco habría sufrido una metamorfosis tal que llegó a implicar la definición del ser y del deber.

El asunto está, a nuestro parecer, en que la figura dionisiaca generalmente ha sido vista como aquello que rompe con los límites de lo socialmente aceptado y permitido. La locura es la divisa de este dios y todo aquel que cae bajo su imperio es percibido y tratado como un loco. Pues bien, la manía encierra toda actitud humana en su definición y en sus acciones. El calificar de cuerdo al sujeto desde una visión estrecha y reduccionista que cercena las posibilidades de la libertad, es negar la esencia de lo dionisiaco. Al negarlo, sobreviene la tragedia. Es decir, lo trágico es un don de Dionisio para aquel que lo rechaza, como Penteo, en las Bacantes de Eurípides, quien, como tirano defensor del orden socialmente coherente, es sacrificado por su propia madre. Ella se halla en el momento de la ejecución bajo el influjo de la locura dionisiaca. La tragedia es evidente en su raíz: no aceptar a Dionisio es abrir una puerta directa a la confrontación del ser. Pero, ¿qué sucede con aquellos que sí siguen a Dionisio e igualmente caen en la desgracia? Otra vez en las Bacantes hallaremos la respuesta: el ser y el deber definen las acciones que delimitan el drama humano. Ágave es proporcionalmente castigada en comparación con su hijo, no obstante que ella permanece viva, pero el asesinato de su hijo la convierte en el móvil de las Erinias, cuya manifestación es común en la metamorfosis y en el exilio, como sucede en este caso. El dios cae sobre estos personajes como un engaño que opone su propia esencia. Ágave, seguidora y sacerdotisa de Dionisio, sufre terrible pena al descubrirse instrumento del dios para castigar a Penteo y a toda su familia. La aphrosyne, otra forma de la locura, es lo que, 
en palabras de Cadmo "reunió a todos en el mismo desastre", pues ya "sin hijos varones" la familia queda cercenada al no existir quien perpetúe la descendencia. ${ }^{5}$

Adviértase el acoso al que se ven sometidos los personajes trágicos: internamente, en el ser, la divinidad impulsa al sujeto a actuar equivocadamente desde el momento en el que se toma la decisión; luego, cuando se ha cometido el error ( $\dot{\alpha} \mu \alpha \rho \tau i ́ \alpha)$, entonces, las Erinias u otras divinidades terribles hacen acto de presencia para agobiar intensamente a quienes han cometido soberbia (üßpıs). De este modo, el personaje trágico navega entre dos terribles olas que lo azotan desde su interior, la Erinia, que no es otro ente que la conciencia, y desde el exterior, la imperiosa necesidad ( $\dot{\alpha} v o ̛ ́ \gamma \kappa \eta)$, que impone una tarea horrenda de cumplir.

En el ámbito del deber llama la atención la razón política que guía a varios de los personajes trágicos. El poder obnubila la razón prudente de los sujetos y los encamina directamente a la desgracia. Edipo, cegado por su celebrada inteligencia, se condena a sí mismo, Penteo muere en defensa de un orden socio-político, Creonte pierde a su familia en aras de hacer valer sus decretos, incluso en la comedia se observa para este fenómeno que la crítica al poder se origina en la extrema burocracia y en la misma guerra, que entre otros motivos hicieron declinar a la democracia.

Si esto es así, entonces el hombre aparece como un ser terrible ( $\delta \varepsilon ı v o ́ s)$, esto es, contradictorio porque es capaz de enfrentarse solitariamente al mundo y al destino, y es monstruoso porque en aras de rehacer el camino que a él le parece lógico llega al asesinato, incluso al de sus parientes más cercanos, porque en su intensa complejidad pretende resolver los enigmas del hombre y su contexto, pero es una nulidad para domeñar su propio ser. De modo sencillo: el mundo y el destino es una unidad que no está resuelta, sino que se le presenta

\footnotetext{
${ }^{5}$ Eur., Bacch., vv. 1305 y ss.
} 
al sujeto trágico como un enigma que, al querer solucionarlo, cae en las redes de la soberbia, pero si no intenta la solución, también se convierte en objeto trágico porque otro decidirá por él y lo conducirá a una respuesta no querida. Ese otro que decide por el sujeto pasivo es, en última instancia, el destino. Así pues, el ser humano es arrastrado por el afán de concebirse y por el apremio de cumplir su tarea como héroe trágico. En este tenor, Vernant ha afirmado que "en el terreno de la experiencia humana, con el advenimiento de lo que puede denominarse una conciencia trágica [...], desde la perspectiva característica de la tragedia, el hombre y sus actos no se perfilan como realidades estables que se podrían delimitar, definir y juzgar, sino como problemas, como preguntas sin respuesta, como enigmas cuyo doble sentido queda siempre por descifrar". ${ }^{6}$ La tragedia es, entonces un proceso que refleja la problemática existencial, ya sea porque el sujeto se siente ajeno de sí mismo o de su contexto. Lo peor que le puede suceder es que en aras de ser o de deber se traicione a sí mismo y, entonces, sólo halle el camino de la muerte como respuesta al drama que vive.

La idea de que nada es estable en la vida del hombre es razón más que suficiente para determinar el grado de la tragedia. Ya en la poesía homérica y en los líricos arcaicos se halla arraigada la imagen de que la humanidad está sujeta a un devenir inestable: el barco en medio del mar, las hojas de los árboles que se suceden estación tras estación, el gozo efímero de las cosas placenteras y la intensidad con la que duran las infaustas, son algunos de los modos en que antes de llegar a ser un género literario, fue pergeñada ya la idea de lo trágico en la épica y en la lírica. Pero, a diferencia del poeta épico o lírico, el dramaturgo presentó a sus personajes como un espejo de la angustia colectiva del sujeto. La tragedia, hemos dicho, es mito en acción, un mito de lo trágico. En efecto, mientras

\footnotetext{
${ }^{6}$ Jean-Pierre Vernant y Pierre Vidal Naquet, 2002, II, p. 25.
} 
que un elegiaco como Arquíloco dialoga con su corazón y en la intimidad de las palabras se reconforta y aconseja, ${ }^{7}$ el poeta dramático lleva al escenario tal diálogo y, entonces, si bien la textura trágica no cesa de ser intimista, el héroe trágico se abre ante el espectador y muestra el sentimiento amargo por partida doble. La individualidad llevó a la reflexión de la soledad del hombre: en ella, la dinámica del ser y del deber actuó para plantear un conflicto irresoluble. Así, el personaje de la tragedia es la realización del sujeto individual en dos sentidos, primero, como apunta Aristóteles, porque hay una clara división del héroe como jefe o rey a diferencia del resto, el pueblo que componía el coro, ${ }^{8} \mathrm{y}$, en segundo lugar, que para la definición de lo trágico es esencial, porque el personaje conforme cumple su destino va quedando aislado hasta que en su inexorable caída no hay nada más que él y su circunstancia. El héroe trágico lucha contra su ser y, al mismo tiempo, el coro es parte del deber que a aquél se le endosa.

Entre la abundancia de definiciones de la tragedia habría una condición insoslayable: la contradicción, el espacio en el que conviven enfrentándose por lo menos dos visiones, dos respuestas, una encrucijada que debe de definir el rumbo del sujeto. Afirma Unamuno: "como que sólo vivimos de contradicciones, y por ellas, como que vida es tragedia, y la tragedia es perpetua lucha, sin victoria ni esperanza de ella; es contradicción". ${ }^{9}$ El origen y el fin de Edipo encarnan el ejemplo de la confrontación aquí definida por el filósofo español.

Ahora bien, la confrontación que hemos venido indicando tuvo un indicio evidente en la máscara trágica. Ésta, si bien pudo tener un origen religioso, en la representación teatral adquirió otros matices, tan profundos que es posible advertir a través de ella una comprensión de la existencia humana, pues

\footnotetext{
${ }^{7}$ Archil. 67a D.

${ }^{8}$ Arist., [Pr.] 19, 48.

${ }^{9}$ Miguel de Unamuno, Del sentimiento trágico de la vida, Buenos Aires, Losada, 1998 (1964), p. 18.
} 
participa de la dualidad dios-hombre, si aceptamos, junto con Otto, que la máscara es una epifanía de Dionisio. ${ }^{10}$ La antigua máscara de los rituales religiosos obedecía, en cierto modo, a la mímesis que el sujeto ejecutaba para explicarse: ya no era él, sino otro que pasaba a formar parte de la naturaleza, quizá porque se advertía, en un momento dado, ajeno ya de ella, y la máscara, como parte de un ritual, indicaba esa pertenencia al cosmos. Y, al mismo tiempo, era signo de la separación. Sin embargo, en la tragedia, la máscara no hacía salir al individuo para que formara parte del todo, sino que lo individualizaba y, al hacerlo, contenía la dialéctica del ser y del deber. Así, la máscara trágica oculta más de lo que en sí refleja. Los gestos que pudiera expresar, de algún modo estáticos en la ejecución de una escena, no eran suficientes para denotar el pathos que implica definir el ser y la pesadumbre que resultaba el cumplimiento del deber. Era, entonces, el artilugio de la palabra el instrumento que revelaba la congoja de los personajes y la tensión de sus acciones. ${ }^{11}$ La máscara debía adquirir los más finos matices del discurso de la tragedia.

Si, como afirma Vattimo, "el problema de la máscara es el problema de la relación entre ser y apariencia", ${ }^{12}$ entonces, como un modo de ocultamiento, la máscara sepulta el ser del individuo y como un medio de proyección al exterior el deber se impone. Tomemos como ejemplo el caso de Electra. Si pen-

${ }^{10}$ Cf. W. F. Otto, Dionysos, Mythos und Kultus, Frankfort, V. Klostermann, 1933.

${ }^{11} \mathrm{Si}$ bien el espectáculo teatral era un todo que conjuntaba los distintos códigos dramáticos - escenografía, coreografía, texto escénico, etcétera-, era tan sólo la palabra lo que guiaba y sostenía la ejecución del drama. Arist., Poet., 50b 17-21, indicaba ya que los sentimientos de lo trágico sólo podían tener causa y efecto a partir del uso de la palabra.

${ }^{12}$ Gianni Vattimo, El sujeto y la máscara. Nietzsche y el problema de la liberación, Barcelona, Península, 2003 (1974), p. 22. La idea señalada es de tal importancia que va más allá de la relación intrínseca con los estudios sobre la tragedia, pues Vattimo analiza el desarrollo de los postulados de "ser" y de "apariencia" a la luz del análisis filosófico y filológico que sitúa a "lo griego" en los extremos de modelo y de decadencia, transitando por el pensamiento de Hegel, Schopenhauer y Nietzsche. 
samos en la definición de su ser, ésta se hallará en las tragedias homónimas de Sófocles y de Eurípides, sobre todo en este último, pero no en Esquilo. No obstante, en los tres casos es inmanente el tópico de la venganza por el asesinato de Agamenón. La tragedia esquilea muestra que no existe un sistema judicial propiamente dicho en manos de los hombres, pues lo que priva es la manera como se desarrolla el orden moral. El cosmos es la razón, su ruptura es lo trágico. ${ }^{13}$ Sobre ésta es posible definir lo que es justo. En el centro de la trilogía esquilea se halla el motivo del matricidio, de suerte que la venganza es válida para el reestablecimiento del orden, el cual se alcanzará en el trocamiento de las Erinias en Euménides y la representación de la nueva sociedad en Zeus, Apolo y Atenea: el nuevo pacto legal. La tragedia de Esquilo está imbuida en un sistema de creencias religiosas enraizadas en la tradición arcaica: la sangre se lava con más sangre, y es el dios flechador quien exige la venganza del crimen que cegó la vida de Agamenón; quien debe ejecutar dicha acción es el príncipe, Orestes. La figura de Electra en las Coéforas es más bien discreta: es un nexo en la anagnórisis que indica la ruta de la venganza. Su participación se reduce a la escena del reconocimiento de Orestes y del kommos que le sigue, pero Esquilo ha marcado el paso para la manufactura de un nuevo personaje trágico, pues Electra alcanza, luego, una mayor dimensión en la tragedia homónima de Sófocles y su figuración conclusiva como mitologema se debe, sin duda, al cálamo de Eurípides.

Para que Electra pueda ser, debe conducir a los amantes a la muerte. El punto álgido se alcanza en el agón que sostiene con su madre, donde se señalan las posturas distintas sobre el deber. ${ }^{14}$ Hay angustia en el momento en el que el personaje tiene que dividir su filiación entre el padre o la madre. Pero, final-

\footnotetext{
${ }^{13}$ Pierre Vidal-Naquet, El espejo roto. Tragedia y política en Atenas en la Grecia antigua, Madrid, Abada, 2004 (2001). Cf. también Jean-Pierre Vernant y Pierre Vidal Naquet, 2002, I, pp. 27-28.

${ }^{14}$ Eur., El., vv. 997 y ss.
} 
mente, observamos que el paso de la estafeta vengadora, en la que madre e hija, Clitemnestra y Electra, asumen el papel de las Erinias, es como si la locura de estos terribles seres las poseyera al grado de hacer de ellas la naturaleza viva de la furia. Así en los vv. 99 y ss. de la Electra euripidea las dos mujeres debieron representar un rostro tal de las diosas vengadoras de sangre, que resulta un intenso enfrentamiento sobre el peso de la sangre del héroe Agamenón. Máscara de la ira soberbia que busca venganza. La sangre con sangre se lava, y fue preciso que la cólera nefasta de Electra se impusiera y de no ser por el juicio de los dioses, según el mito, aquélla habría seguido derramándose.

Otra figura asociada con la representación de la máscara es la Gorgona. Su rostro manifiesta notablemente la significación de lo trágico, pues a través de la alegoría que los dramaturgos dibujaban con palabras para la tragedia de sus personajes es como se halla una representación de lo trágico: Edipo Tirano debió aparecer en la entrada de la tragedia de Sófocles con una máscara que reflejara la potestad de rey-sabio, de aquel que detenta el poder de modo absoluto y, al final de dicha obra, lo hallaríamos con otra máscara, con las cuencas de los ojos vacías y, quizá, con sangre corriendo figuradamente por sus mejillas. Es un rostro gorgónico, cuya vaciedad en la mirada es, como la de la Grea mortal, el camino hacia el más allá. La ceguera de Edipo es metáfora de la muerte en vida. En otro caso, Eurípides perfila el rostro colérico de Heracles que ya no es más su faz, sino la de un ser monstruoso: "Heracles ya no era el mismo: alterado en el movimiento de sus ojos y dejando ver en ellos las raíces enrojecidas, arrojaba espuma sobre su barba bien poblada. Y dijo de pronto con risa enloquecida". Los sirvientes se preguntarán, luego, si su amo está loco. En efecto, lo está. Lo locura transforma el rostro del héroe hasta hacerlo desconocido. ${ }^{15}$ La locura es la antesala de

\footnotetext{
${ }^{15}$ Eur., Her., vv. 931 y ss.
} 
la perdición. Y, como se ha demostrado, la locura proviene de dios. $^{16}$

Esta forma de ver la tragedia que azota desde el exterior y se convierte en una fuerza interna que va socavando el ser del individuo tiene su explicación, entre otras formas simbólicas y narrativas, en la metamorfosis. La máscara revela una metamorfosis. No habría que esperar una transformación absoluta del ser para comprender que en él se opera un cambio radical. El tratamiento del mito de Ío en Prometeo encadenado es un ejemplo concreto de sujeción de lo trágico como mero acto gratuito que alcanza su punto álgido en la metamorfosis. La gratuidad se comprende en la medida en que se aprecia el ejercicio violento del poder de Zeus sobre la doncella. El dios la quiere poseer y es a través del sueño como manifiesta su deseo de yacer con ella, al llamarla a pastar a los prados de Lerna. El sueño se interpreta de tal suerte que la doncella, metamorfoseada en vaca, es exiliada por su padre. Ío, acosada por el tábano enviado por Hera, realiza un viaje de iniciación que la convertirá en una deidad, al amparo del Cronida. El actor portaba, sin duda, una máscara que representó al personaje mitológico con el rostro vacuno. La alegoría de la máscara vacuna comporta el tránsito por lo trágico y, luego, habría que suponer que, concluido el viaje, Ío recuperaría su faz de doncella. El tábano refiere, como el sueño, el elemento externo que conduce a la locura: ${ }^{17}$ si "las miradas nocturnas" perturban el pensamiento de la doncella al grado de confinarla, el tábano enloquece a Ío porque no le permite un momento de descanso, esto es, se trata de un padecimiento físico, que tiene a la sinrazón como elemento análogo del castigo por el amor del dios oculto en el sueño. Así pues, la tragedia de Ío, si bien pasajera, es la indefinición que marca la metamorfosis entre ser humano y vaca; es la confrontación de ambas naturalezas

\footnotetext{
${ }^{16}$ Ruth Padel, A quien los dioses destruyen. Elementos de la locura griega y trágica, México, Sexto piso, 2005, passim.

${ }^{17} P V$., vv. 567 y ss.
} 
en el otro que se define en el viaje, donde habita lo bárbaro y lo monstruoso, entre la cordura y la locura. ${ }^{18}$

La locura no es un estado excepcional del sujeto, si acaso es opacada por las reglas políticas, pero siempre está latente. Si el personaje actúa en relación con la civilidad imperante, entonces se le tiene por sensato, no obstante que puede no estar de acuerdo con las causas que lo llevan a ser y a actuar de ese modo. Ismene manifiesta prudencia al tratar de hacer que Antígona recule en su intento de dar sepultura a su hermano Polinices, para no padecer la justicia decretada por Creonte:

Y ahora, al contrario, solas nosotras dos como hemos quedado, considera con cuánto mal sucumbiremos, si forzando la ley, no hacemos caso del decreto o del poder del tirano. Antes bien, es preciso que pensemos esto: nacimos mujeres, no hechas para luchar contra los hombres; luego, nos gobiernan los que tienen mayor poder, y estas cosas hay que obedecer y aún aquellas más dolorosas. ${ }^{19}$

Las palabras de Ismene no están exentas de razón. Pero Antígona también esgrime un juicio irreprochable:

Mas sé tú como te parezca y yo a aquél lo enterraré. Bello será para mí hacerlo y morir. Con él, a quien amo y me ama, yaceré, luego de llevar a cabo un piadoso crimen, pues es mayor el tiempo en que debo ser grata a los de abajo que a los de aquí. Allí para siempre yaceré. Y tú, si lo tienes a bien, los honores de los dioses deshonra. ${ }^{20}$

${ }^{18}$ Ruth Padel, op. cit., p. 40. Cf. Froma Zeitlin, "Playing the Other: Theater, Theatrically and the Feminine in Greek Drama", en J. J. Winkler y F. Zeitlin, Nothing to do with Dionysos? Athenian Drama in its Social Context, Princeton, Princeton University Press, 1992, pp. 63-93.

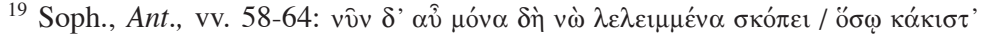

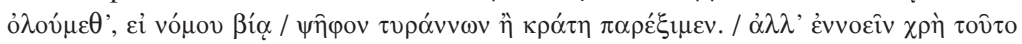

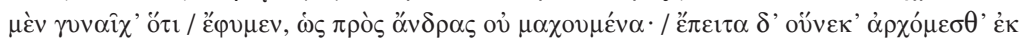

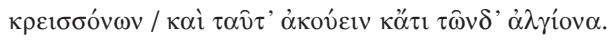

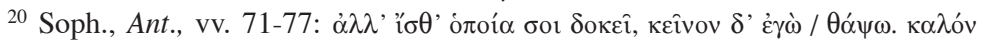

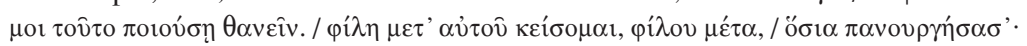


Y entonces también ella tiene razón. La razón de Ismene es enteramente humana y, por lo mismo inmediata, como el dolor que experimentaría si fuera contra las leyes de su tío. La razón de Antígona está dada por una cuestión religiosa, igualmente válida, pues el dolor que en vida pudiera sufrir no se compara con la eternidad que subyace en su razonamiento. Si esto es así, cuál de las dos padece la locura que acorrala en el redil de la tragedia. A diferencia de Esquilo, quien determinaba en la trilogía la restauración del cosmos, es decir, de la razón a través del juicio que reconciliaba lo humano y lo divino, Sófocles mantiene al sujeto en la incertidumbre, porque no se resuelve el dilema y queda latente el meollo de lo trágico. No obstante, observemos que el cosmos esquileo está apoyado sobre fuerzas en tensión: la nueva religiosidad y la legalidad del desarrollo político no sustituirían del todo a las antiguas creencias, esto es, que el trocamiento de las Erinias en Euménides es la fundación de un nuevo orden jurídico sobre la base de una ética enraizada en el terror inherente de las diosas vengadoras de los delitos de sangre. Por su parte, Eurípides mantiene también la incertidumbre al representar la trama, pero algunos de sus personajes se mantienen dentro de un paradigma de locura trágica que define su naturaleza, es decir, la decisión tomada dirige sus pasos en todo momento, a veces titubean, pero su intención prevalece y, entonces, la locura es su modo de vida, esto es, no hay límites entre la razón y lo opuesto. O mejor dicho, la locura es el estado de la razón, de su razón por lo menos, por ello aparecen ante los otros como personajes fuera de sí, del control, de lo civilizado y de lo político.

Si esto es así, la tragedia se perfila como una postura que contiene dos premisas irreconciliables, donde no necesariamente una de ellas contiene la verdad o la razón. Se ha queri-

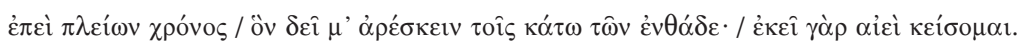

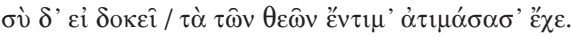


do ver en esta variable una influencia de la retórica y de la sofística en el desarrollo de la tragedia. ${ }^{21}$ Quizá sea lo contrario: la tragedia por esencia es el estado de la contradicción. Las oposiciones son síntoma de la presencia de lo dionisiaco, pues este dios se caracteriza por ser otro modo de razonar. ${ }^{22}$ No es necesaria la oposición, incluso, de dos personajes. Basta con que uno de ellos entre en conflicto con su ser y con su deber. Ha sido el sentido lógico que se pretende aplicar a la vida del hombre lo que niega la trascendencia de lo trágico. Pero esta misma situación encamina al dilema, pues cuando la lógica ya no da más de sí, sobreviene la disputa con el otro o consigo mismo. La lógica del que niega la locura es otra manera de nombrar a ésta.

La negación de la lógica se explica desde el terreno del pathos. Los sentimientos y las pasiones del hombre son indicio de que la tragedia está en camino. Cuando se llega a la locura, el personaje no es capaz de gobernar todo aquello que de su interior explota como pasión y emoción. Homero en una sola imagen define cómo nacería la tragedia desde el interior del ser, atendiendo la raíz del pathos: cuando el corazón y la mente entran en conflicto (Il., I, 188-189; 334; IV, 668). Este conflicto es lo que impele al individuo a actuar en la definición del ser, pero desde el plano de las pasiones. En Prometeo encadenado, Ío refiere que "el corazón golpea de miedo mi pecho" (v. 881). De un modo más amplio, Arquíloco, como forma de la phren, dialoga con su corazón y le aconseja mesura ante la derrota o el triunfo, a evitar la hybris que implica ufanarse o echarse a llorar; ante todo, afirma el poeta, lo que impera es la alternancia. ${ }^{23}$ Ahí está el debate del sujeto consigo mismo para tratar de hallar una salida a la desgracia. Por ejemplo, Medea duda ante el hecho de matar a

\footnotetext{
${ }^{21}$ V. Goldschmidt, Questions platoniciennes, Paris, J. Vrin, 1970, pp. 103-140.

${ }^{22}$ Cf. M. Daraki, Dyonisos et la Déesse Terre, Paris, Champs-Flammarion, 1994, passim.

${ }^{23}$ Archil. 36, 1-7 L; 58 D; 67a D.
} 
sus hijos: la pasión y la acción de la venganza como modo de hacer justicia se confrontan en el interior de esta mujer, quien finalmente deja que Jasón viva para que padezca la muerte de su prometida y de sus propios hijos. ${ }^{24}$ Haber dado muerte a Jasón, hubiera significado resolverle la vida, es decir, solucionar su tragedia; en cambio, al seguir viviendo, la locura, en forma de conciencia, lo perseguiría recordándole el error que cometió al haber traicionado a Medea.

Las pasiones que bullen en el interior del sujeto afectan inevitablemente a la conciencia, al punto de que aquélla derrota a ésta o en la confusión de la batalla el hombre se obnubila y actúa creyendo que hace lo adecuado, cuando en verdad solo deviene en paciente de lo trágico. El individuo que busca definir su existencia, ya sea porque él así lo ha decidido concientemente o ya sea porque el destino lo ha colocado en tal circunstancia, es golpeado ( $\pi \alpha \rho \alpha ́$ ко $\pi \circ \varsigma$ ), y dicha violencia puede encaminarlo a la locura y, de ahí, a la tragedia. Más que picada por el tábano, Ío es golpeada por éste: es el golpe físico, gratuito además, que hace que la doncella corra errabunda y errante.

En el Agamenón, el coro explica, al hacer un recuento de los antecedentes de la vuelta del héroe a su palacio, el motivo de la punición que lo alcanza en manos de Clitemnestra y Egisto: el sacrificio de Ifigenia. Dos cosas llaman la atención a partir del v. 176 de esta tragedia: primero, el coro prologa la decisión del héroe al abundar sobre el conocimiento y el sufrimiento. El coro indica que "el camino del saber" ( $\varphi \rho o v \varepsilon i ̂ v$ ó $\omega ́ \sigma \alpha \nu \tau \alpha)$ se hace con malestar. No se trata sólo del "saber" que da una techne o la episteme al hombre, sino el aprendizaje que lleva al individuo a la prudencia ( $\sigma \omega \varphi \rho o v \varepsilon i v)$, a ser capaz de refrenar la hybris. Y, como hemos visto, el pathos cobra presencia inmediata como síntoma de la tragedia: "Del cora-

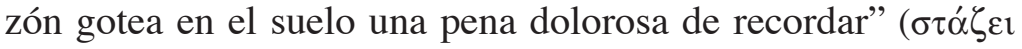

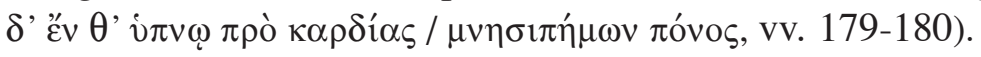

\footnotetext{
${ }^{24}$ Eur., Med., vv. 1236 y ss.
} 
El aprendizaje es obligatorio cuando se debe tomar una decisión. De hecho, el saber es fuente de tragedia, no sólo porque, como señala Aristóteles, constituye el momento en el que el individuo pasa de la ignorancia al conocimiento, la anagnórisis, ${ }^{25}$ sino también porque éste entraña de suyo un carácter trágico en la medida en que el hombre ingresa en el incesante acto de cuestionar. Y peor si lo que indaga son las razones del destino en su hic et nunc, porque entonces la locura se hace presente. Así, Agamenón se ve en la imperiosa necesidad de sacrificar a su hija Ifigenia a fin de que su ejército pueda sortear "los

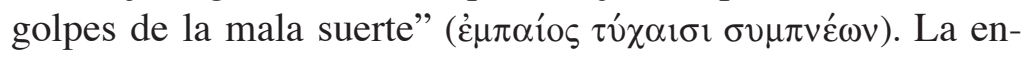
crucijada hace reflexionar al héroe $\mathrm{y}$, a pesar de que puede tener noción de que lo que decida, salvar a su ejército o a su hija, tendrá consecuencias nefastas, opta por manchar sus manos con sangre de su propia sangre. La reflexión es, entonces, parte de la locura. El coro lo expresó así:

Y cuando se unció al yugo de la necesidad, de su mente un viento diferente exhaló, impío, sacrílego, con el que cambio de sentimientos y con insolencia a todo se decidió, que a los mortales enardece la funesta locura. ${ }^{26}$

En tales versos hallamos, en resumen, un camino de lo trágico: primero, la ineluctable necesidad es la encrucijada del destino, donde el sujeto decide y se equivoca, lo que lo torna en un hybristés; segundo, es común la metáfora que indica el movimiento o exhalación de las pasiones en el interior del sujeto que, como un veneno, transita el cuerpo, lo que, en tercer lugar, llega a la mente y hace actuar al hombre bajo la potencia de la locura.

Unamuno se preguntó por qué no se dijo que el hombre "es un animal afectivo o sentimental", en lugar de "animal racio-

\footnotetext{
${ }^{25}$ Arist., Poet., 52a29-52b1.

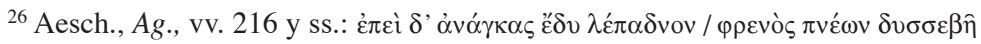

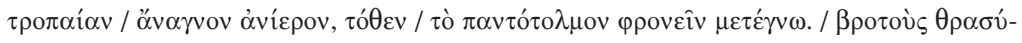

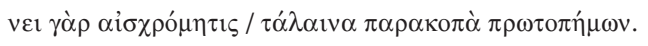


nal". Y es sobre todo "el sentimiento lo que hace la diferencia entre los hombres y los animales". ${ }^{27}$ La locura es una forma de ser, como tantas otras, con la advertencia de que, como ha estudiado Ruth Padel, quizá ésta involucre a todas las demás maneras de ser y la aparición del hacer es lo que detona la tragedia. El ser humano que se enfrenta a su ser para derrotarse y el que es sumiso al deber, nunca llegan a definirse. Y es que la definición del ser y del deber puede ser, según expuso Gide, como el águila de Prometeo: el ser humano es quien alimenta la esencia del ser conciente, pero luego la conciencia se vuelve tan obesa, comiendo nuestro hígado/alma, que ya no se vive más. ${ }^{28}$ Se sobrevive en medio de la angustia y de la locura. Tal es la tragedia humana.

\footnotetext{
${ }^{27}$ Miguel de Unamuno, op. cit., p. 9.

${ }^{28}$ André Gide, Prométhée mal enchaîné, Paris, Gallimard, 1992 (1925).
} 